\title{
The qualification of e-learning for higher education through the development of affective usability, self-evaluation test and virtual laboratory ${ }^{1}$
}

\author{
Biasi, Valeria and Ciraci, Anna Maria \\ Department of Education, "Roma Tre” University, Italy
}

\begin{abstract}
This contribution presents some aspects of the Department Interdisciplinary Research Project (PRID) of Roma Tre University. The main aim of the project is to define an innovative e-learning integrated didactic model that can promote the acquisition and development of skills for Lifelong Learning (European Parliament \& European Council, 2008). To this end, the implementation of the following essential variables and components of the Integrated Model is a priority: 1) the learners' motivational involvement; 2) the quality of the experience of immersion within a virtual environment; 3) evaluation and self-evaluation practices. Considering the original model successfully experimented in the Degree Course in Education Sciences at "Roma Tre" University (Domenici, 2016) and particularly focused on evaluation and self-evaluation processes, we propose an implementation of so-called affective usability of the e-learning platform by creating relaxing, stimulating and aesthetic online environments, promoting a greater immersive capacity. To this must be added the students' use of advanced ICT programs enabling them to experience scientific demonstrations and experiments in order to acquire a scientific mentality through the use of Context Simulation Tests and Virtual Didactic Laboratories (VDLs). The effectiveness of implementing the FAD e-learning system in acquiring the scientific thinking modality will be empirically assess.
\end{abstract}

Keywords: Affective usability; Context Simulation Tests; Motivational involvement and immersion; Scientific thinking; Self-evaluation test; Virtual Didactic Laboratories.

\footnotetext{
${ }^{1}$ This article is the result of the joint work of the two authors, in particular the first author wrote paragraphs $1,3,5$ and the second author wrote the paragraphs 2 and 4 .
} 


\section{Introduction: determining factors for qualifying e-learning systems for higher education}

The international literature on problems concerning the learning process in distance education through e-learning platforms shows a numbeår of determining factors for qualifying this educational modality: variables concerning the learners' motivational involvement; the quality of experience within the virtual environment; familiarity with information and communication technology (ICT); evaluation practices; the characteristics of the learning materials, environments and experiences; and the institutional, organizational and management aspects.

This contribution presents some aspects of the Department Interdisciplinary Research Project (PRID) "E-learning per l'istruzione superiore: definizione di un modello integrato per la qualificazione degli apprendimenti e delle relazioni educative on line" ("E-learning for higher education: the definition of an integrated model for qualifying learning and educational relations on line"), still in progress, of the Department of Education of Roma Tre University. The main aim of the project is to define an innovative e-learning integrated didactic model that can promote the acquisition and development of skills established in the European Qualifications Framework for Lifelong Learning (European Parliament \& European Council, 2008).

To this end, the study and implementation of the following essential variables and components of the Integrated Model is a priority: 1) the learners' motivational involvement; 2) the quality of the experience of immersion within a virtual environment; 3 ) evaluation and self-evaluation practices.

As we know, e-learning evaluation practices require particular attention also in view of their metacognitive functions. In online education, perhaps even more than in traditional classroom education, a key role is played by the capacity for self-regulation and selfevaluation in one's study (Trinchero, 2006; Domenici, 2009; and others). In particular, we believe the new forms of self-evaluation of learning acquired through semi-structured tests (Domenici, 2005; Ciraci 2017), especially of the context-simulation types, are better in conditions of good immersion within a virtual learning environment. Such a good immersion is made possible in the case of good interaction between the ICT system and human verbal and non-verbal language, and may be achieved by such things as resorting to relaxing colours and clear non-fragmented icons, thereby avoiding an overload or bombardment of heterogeneous information and favouring guided forms of reading and summarizing of texts under study.

One should also take the user's or student's average motivational makeup and his/her range of cognitive interests into account in order to calibrate the didactic message to catch his/her 
attention and promote positive emotional involvement facilitating learning processes themselves (Biasi, 2017; Domenici, 2017).

Hence, we propose the implementation of an original model successfully experimented over the last fifteen years in the Degree Course in Education Sciences at Roma Tre University (Domenici, 2016) and particularly focused on evaluation and self-evaluation processes. This implementation envisages the enhancement of so-called affective usability of the e-learning platform by creating relaxing, stimulating and aesthetic online environments, and devoting great care to graphic and dynamic aspects thereby stimulating a greater immersive capacity on the user's part within the e-learning environment.

To this must be added the students' use of advanced ICT programs enabling them to experience scientific demonstrations and experiments in order to acquire a scientific mentality. It means, ultimately, broadening the use of context simulation tests to arrive at creating real Virtual Didactic Laboratories (VDLs) through which to enhance scientific thinking by stimulating occasional observation, the problematization of a phenomenon, systematic observation, hypothesis generation, the devising of experiments or demonstrations, and data gathering for hypothesis testing.

\section{The FAD organizational-didactic model of the Degree Course in Education Sciences at Roma Tre University: the outcome of field research}

The Departmental Interdisciplinary Research Project (PRID) took off from the outcomes of several empirical studies carried out within the Degree Course in Education Sciences in FAD (Formation at Distance) modality on an e-learning platform of Roma Tre University, dedicated to teacher-training, in which the integrated organizational-didactic model proposed by Gaetano Domenici (2016) has been successfully tested over the last fifteen years. The distinguishing and innovative feature of this course is the didactic methods which, also thanks to network enhancement, are based not so much on pre-constituted knowledge as on real simulations of events situated in teaching contexts, and on evaluation and self-evaluation tools that facilitate experiential learning to raise awareness of one's own cognitive processes and the capacity to devise problem-solving strategies (Ciraci, 2009). The results of two important Research Projects of National Interest (PRIN) conducted within the aforesaid degree course have shown the crucial importance of variables like evaluation and self-evaluation processes in the qualification of e-learning. A first study (Domenici, 2009) confirmed the existence of a positive correlation between systematic selfevaluation processes of acquired competencies, on one side, and performance (average grades, number of exams and number of credits), on the other. The subsequent research project of national interest (Domenici, 2017) investigated the effects of the skills gained by the teacher-participants on their professional work following a training course based on the 
aforesaid FAD organizational-didactic model. An analysis of the data gathered by means of course entrance and exit questionnaires given to the teachers of the Experimental Groups (EGs), that is, the teachers undergoing training, shows a clear increase in the use of theoretical-operational context stimulation tests $(+33 \%)$ and of problems derived and situated by/in real life contexts $(+41.6 \%)$ (Table 1), among the considerable number of testing tools normally used by teachers to assess learning, as well as a greater use of selfevaluation. These outcomes clearly show a general effect of maturation of didactic and evaluative skills of the EG teachers after their training experience, and point to the capacity to arrange formal learning contexts geared to promoting students' development of those fundamental structures of "self-regulation" represented by the capacity to monitor one's own learning process and thus to self-evaluate and self-correct oneself.

Table 1. Instruments used by the EG teachers to assess learning

\begin{tabular}{llc}
\hline Testing instrument & Entry & Exit \\
\hline 1. Laboratory tests & 22.9 & 35.42 \\
\hline 2. Traditional type problems & 27.1 & 56.25 \\
\hline 3. Summaries & 25.0 & 35.42 \\
\hline 4. Objective tests (multiple-choice, true/false, cloze, matching) & 52.1 & 87.50 \\
\hline 5. Short essays & 18.8 & 27.08 \\
\hline 6. Traditional essays & 27.1 & 35.42 \\
\hline 7. Individual research projects & 31.3 & 60.42 \\
\hline 8. Theoretical-operational context simulation tests & 10.4 & 43.75 \\
\hline 9. Structured questions (series of questions with short answers & 47.9 & 75.00 \\
and subject to predefined constraints) & & \\
\hline 10. Case studies & 4.2 & 22.92 \\
\hline 11. Problems derived and situated by/in real life contexts & 29.2 & 70.83 \\
\hline 12. Reading comprehension tests & 45.8 & 70.83 \\
\hline 13. Other & 6.3 & 20.83 \\
\hline
\end{tabular}




\section{Developing user interest and attention by enhancing affective usability}

As regards the affective variables, the specialist literature often stresses the role of intrinsic motivation in facilitating learning in the e-learning mode. Zaharias (2009) stressed how non-motivated adults, in particular, drop out of e-learning courses and suggests including an affective dimension of learning among the factors facilitating "usability" - that is, which make the adoption and use of new technologies in educational systems ("e-learning usability practice") possible. He suggests considering this factor a new type of "usability dimension" in programming and evaluating e-learning applications.

These studies integrate the view that motivation has an initial effect particularly on metacognition (self-efficacy, self-regulation, etc.). Mammarella, Cornoldi and Pazzaglia (2005) highlighted how several perceptual and attentive processes interact in e-learning and how they affect individual differences (such as with different learning styles with respect to the way information is presented, and so on). It is a fact that discussion forums, chat sessions and other interaction environments go to make up a virtual space where users can also take emotional contents into account as integral parts of their learning process. The results of a comparative study on various interactive contexts show a preference for multimodal systems which manage to integrate forms of communication that are familiar to participants.

Hence, studies on affective and cognitive processes in various educational contexts are of great interest today and they also include e-learning (Magno Caldognetto \& Cavicchio, 2008; Fielder \& Beier, 2014).

With regard to the overall list of motivations (Biasi, 2017), the ones mainly involved in elearning processes are: a) "Motivation to knowledge", which concerns information gathering and the construction of concepts or mental schemas. It includes aspects of ordered knowledge typically referred to convergent and divergent or creative cognitive skills; b) "Motivation to self-assertiveness", which is expressed in behaviours geared to asserting oneself in order to achieve goals experienced as positive, including educational results in view of such things as career prospects; c) "Motivation to sociality", which includes attractive relational aspects with the "other than oneself", experiences of socialness and imitation of others' behavioural models by identification. It can be activated by situations of social isolation and loneliness. It could also activate recourse to various means of communication (such as a telephone, television, networked computer, e-mail, chat or discussion forum interventions). As regards the role of psychological variables like the promotion of positive valences in didactics (such as emotional involvement and aesthetic experience), there are various contributions in the national and international literature (Metzger, 1965; Bonaiuto, 1972). There is general agreement on the fact that originality, elegance, competence and authenticity in didactic communication have important functions 
in arousing motivational commitment, attention, facilitation in understanding and learning, and are also articulated with the educational style and manners of interpersonal relations. Similar features can be explored with regard to the quality of environments and of texts necessary for study (Biasi, Bonaiuto \& Cordellieri, 2004).

These components can be appropriately enhanced through multimedia technologies, which manage to broaden the teacher's personal aptitude and can assure greater experiencing of interpersonal contact - something which, at least from a psychological point of view, needs to be strengthened and promoted in e-learning.

\section{Context simulation for learning process governance}

Adults are generally more disposed to learning what is concretely usable and effective, even indirectly, in real life situations, compared to what is not (Bandura, 1997). Thus, adult students require didactic methods which, thanks to the potential of new technologies, are based not so much on the transmission of pre-constituted knowledge as on the proposal of activities through Virtual Didactic Laboratories (VDLs) in the form of simulations of events situated in working contexts.

As we know, simulation techniques are increasingly more important, particularly in decision-making situations. In the didactic-evaluation field, they are expressed in methodologies which reject a passive, dependent and largely receptive role of the student in favour of his/her conscious participation because they contextualize learning situations in real environments like the ones the student has experienced in the past (the actualization of experience), the one s/he is experiencing now or will do so in the future (forecasts and virtuality). The theme of competences, meant as the "ability to apply knowledge, skills and personal, societal and/or methodological capacities in work or study situations and in one's personal and professional development" (European Parliament \& European Council, 2008) with a view to learning that is no longer limited to schooling years but extended to one's whole life, has led to a change in direction in the international sphere with regard to the tools for their evaluation(Baker, 2007). In the FAD organizational-didactic model (Domenici 2016) the didactic proposal is characterised by the systematic use of structured evaluation and self-evaluation tests with a view to metacognitive control. In particular, in evaluation and self-evaluation processes, semistructured tests are used (Domenici, 2005; Ciraci 2017) in the context simulation typology which, unlike the tests normally used, make reference to complex uncertain problems such as the ones normally found in everyday life and enabling students to take decisions, observe the consequences and to reflect on wrong or incomplete outcomes, thereby placing students in control of their own learning processes (Domenici, Biasi \& Ciraci 2014). 


\section{Empirical application of the Implemented FAD Prototype-Model (FAD-I): indications for developing scientific thought in higher education}

The empirical application of the Implemented FAD Prototype-Model (FAD-I) involves an enrichment of the virtual learning environments by devoting attention to the graphicpictorial aspects expressing comfort and aesthetic value, a refinement of the appeal of icons, an improvement of accessibility - sometimes in a playful manner, the enhancement of dynamic and cinematic expressiveness, and the availability of guided paths also with the assistance of remote tutors.

Decisions relating to such things as the images used must be made, where possible, in accordance with the users' main cognitive interests (e.g. for students of artistic disciplines or of humanities, or even of biomedical or physical-mathematical, juridical or economic fields).

Tutoring, chat and forum sessions must be guaranteed to meet the main needs of the average user. As specified in section 1 of this paper, it is generally a question of motivation to sociality, to self-assertiveness and to knowledge, which are all particularly important in e-learning.

At this point, the Virtual Didactic Laboratories (VDLs) are proposed as disciplinary didactic interventions on themes of interest in the various subjects. The test of empirical application of the implemented FAD model was carried out within the Education Sciences degree course implemented on the e-learning platform of the Department of Education of Roma Tre University.

During the final stage of students' training, thanks to their participation in e-learning classes (lasting 6 months), the students' capacity to apply scientific reasoning in the approach to knowledge was also assessed (involving such things as occasional observation, the problematization of a phenomenon, systematic observation, the formulation of hypotheses, the devising of experiments or demonstrations, the gathering of data for testing these hypotheses, and the analysis of data and their critical interpretation). To assess the strengthening of scientific thinking, structured and semi-structured (problem-solving) tests will be used with context simulation. These tests will be given to both the student group carrying out the virtual laboratory didactic activities in the semester (the experimental group) and also to a control group made up of students not taking part in the above laboratory activities. To empirically assess the effectiveness of implementing the FAD elearning system, the differences in average scores recorded by the two groups in the context simulation tests will be analysed. We hypothesize a significant increase in acquiring the scientific thinking modality for the experimental group compared to the control group. Domenici, Biasi \& Ciraci 2014). 


\section{Conclusions}

We can conclude that the implementation of: 1) the learners' motivational involvement, 2) the quality of the experience of immersion within a virtual environment, 3) the evaluation and self-evaluation practices, will play a key role for self-regulation of learning and scientific attitude. The students' use of this advanced ICT programs based on Context Simulation Tests and Virtual Didactic Laboratories (VDLs), will enable them to experience scientific demonstrations and experiments in order to acquire a scientific mentality. Moreover, the implementation of these cognitive and motivational aspects will contribute to an increase in efficiency of e-learning system.

\section{References}

Baker, E. (2007). Moving to the Next Generation System Design: Integrating Cognition, Assessment, and Learning. Los Angeles, CA: National Center for Research on Evaluation, Standards, and Student Testing (CRESST), University of California.

Bandura, A. (1997). Self-Efficacy: The exercise of control. New York: Freeman.

Biasi, V., Bonaiuto, P., \& Cordellieri P. (2004). La componente estetica nella comunicazione didattica. Opportunità offerte dalle nuove tecnologie. Tecnologie Didattiche. 1, 4-13.

Biasi, V. (2017). Dinamiche dell'apprendere. Schemi mentali, interessi e questioni didattico-valutative. Roma: Carocci.

Bonaiuto, P. (1972). Indicazioni psicologiche per la didattica delle arti visive. La Biennale di Venezia, 67/68, 18-42.

Ciraci A.M. (2009). La formazione universitaria a distanza degli insegnanti: ruolo dell'autovalutazione e ricadute delle competenze acquisite sull'attività professionale. In G. Domenici (a cura di), Valutazione a autovalutazione per la qualificazione dei processi formativi e-learning (pp. 93-112). Lecce: Pensa MultiMedia.

Ciraci, A.M. (2017). Processi valutativi e autovalutativi. Le prove semistrutturate. In G. Domenici (a cura di), Successo formativo, inclusione e coesione sociale. Strategie innovative. Volume primo: Strategie didattiche integrate per il successo scolastico e l'inclusione (pp. 270-277). Roma: Armando.

Domenici, G. (a cura di). (2005). Le prove semistrutturate di verifica degli apprendimenti. Torino: UTET.

Domenici, G. (a cura di). (2009). Valutazione e auto-valutazione per la qualificazione dei processi formativi e-learning. Lecce: Pensa Multimedia. 
Domenici, G. (a cura di). (2016). La formazione on-line a Roma Tre. L'esperienza del Corso di Laurea in Scienze dell'Educazione. Roma: Armando.

Domenici, G. (a cura di). (2017). Successo formativo, Inclusione e Coesione Sociale: Strategie Innovative. Strategie didattiche integrate per il successo scolastico e l'inclusione. Volume Primo. Roma: Armando.

Domenici, G., Biasi, V., \& Ciraci, A.M. (2014). Formazione e-learning degli insegnanti e pensiero creativo (e-Learning Teacher's Training and Creative Thinking). Journal of Educational, Cultural and Psychological Studies 10, 189-218.

Fielder, K., \& Beier, S. (2014). Affect and Cognitive Processes in Educational Contexts. In P.A. Alexander, R. Pekrun, \& L. Linnenbrink-Garcia (2014). International Handbook of Emotions in Education. London: Routdledge.

Magno Caldognetto E., \& Cavicchio F. (a cura di). (2008). Aspetti emotivi e relazionali nell'E-learning. Firenze: Firenze University Press.

Mammarella N., Cornoldi C., \& Pazzagli F. (2005). Psicologia dell'apprendimento multimediale. E-learning e nuove tecnologie. Bologna: Il Mulino.

Metzger W. (1965). The influence of aesthetic examples. In G. Kepes (Ed.). Education of Vision. New York: Braziller.

Parlamento Europeo \& Consiglio Europeo (2008). Raccomandazione del Parlamento Europeo e del Consiglio sulla costituzione del Quadro europeo delle qualifiche per l'apprendimento permanente, Bruxelles (http://eur-lex.europa.eu/).

Trinchero R. (2006). Valutare l'apprendimento nell'e-learning. Trento: Erikson.

Zaharias P. (2009). Usability in the context of e-learning: A framework augmenting "tradition" usability constructs with instructional design and motivation to learn. International Journal of Technology and Human Interaction (IJHI). 5 (4), pp. 37-59. 